To the Editors:

\title{
Anatomy of the Calot's triangle and its relevance to laparoscopic cholecystectomy
}

Laparoscopic cholecystectomy has now become the gold standard treatment for symptomatic gall-stone disease (i). Injury to the common bile duct (CBD) is the major complication of laparoscopic cholecystectomy. Use of diathermy or clips to control bleeding in the Calot's triangle is recognised as one of the commonest causes of CBD injury (2). Hence a detailed knowledge of the vascular anatomy of this region is important to the surgeon to prevent haemorthage in the Calot's triangle.

Detailed dissection of the vascular patterns of the Calot's triangle was performed on $\mathbf{5 0}$ freshly refrigerated bodies of Sri Lankan subjects. As the creation of a circum- ferential window at the infundibulo-cystic duct junction is an important step in the operation, special emphasis was laid on this area to detect the presence of any vessels. Length and mode of insertion of the cystic duct to the common bile duct were documented.

Mean length of the cystic artery was $2.3 \mathrm{~cm}$. (range 1.8 to $2.9 \mathrm{~cm}$ ). The commonest vessel of origin of the cystic artery was from the right hepatic artery (96\%) and the rest were from the common hepatic artery. Figure shows the course and variations of the cystic artery in the Calot's triangle. 


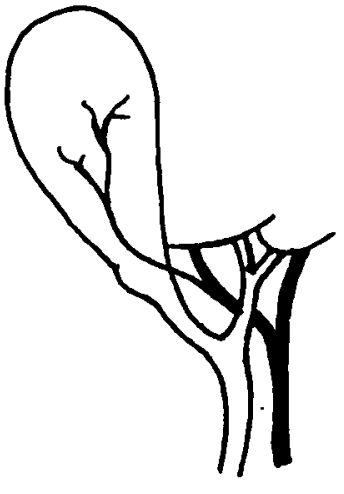

$70 \%(n=35)$

(a)

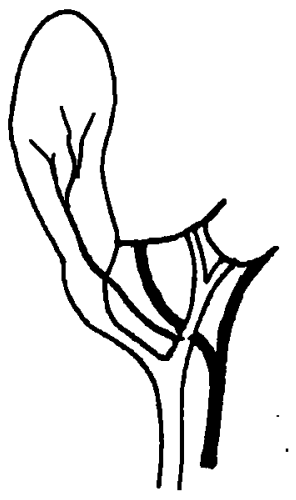

$2 \%(n=1)$

(b)

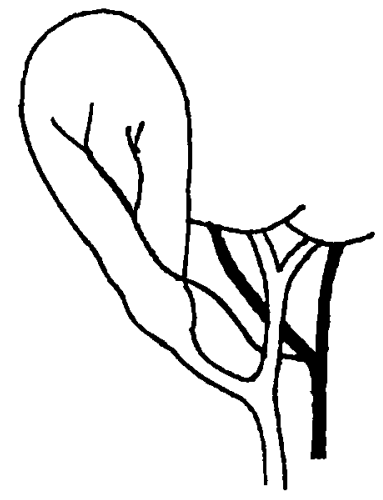

$14 \%(n=7)$

(c)

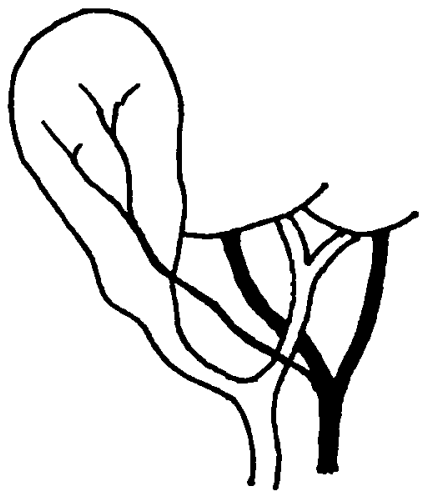

$14 \%(n=7)$

(d)

Figure. Course and variations of the cystic artery in Calot's traingle.

Mean length of the cystic artery was $2.7 \mathrm{~cm}$. Angular insertion was the commonest mode of insertion of the cystic duct to the common bile duct. A spiral insertion was recognised in one case. A significant vessel was observed entering the infundibulo-cystic duct junction only in 3 out of 50 dissections, which indicates that creation of a window at this point is a safe surgical procedure.

This study performed concurrently with the commencement and establishment of the laparoscopic cholecystectomy service in our institution, validates the belief that there is much variation in the vascular pattern of the extra-hepatic biliary tree. It is necessary for the surgeon to be famil- iar with and to recognise these normal variations when present, to reduce the complications of laparoscopic cholecystectomy.

\section{References}

1. Macintyre MC, Wilson RG. Laparoscopic -cholecystectomy. British Joumal of Surgery 1993; 80: 552-9.

2. Gadacz TR. US experience with Laparoscopic cholecystectomy. The American Journal of Surgery 1993; 165: 450-4.

3. Davidoff Am, Pappas TN, Murray EA, et al. Mechanisms of major biliary injury during laparoscopic cholecystectomy. Annals of Surgery 1992; 215: 196-202.

Mohan de Silva, Senior Lecturer and Dayasiri Fernando, Professor, Department of Surgery, Faculty of Medical Sciences, University of Sri Jayawardenepura, Nugegoda. 